W R MURRAY

Dept of Surgery,

Western Infirmary, Glasgow G11 6NT.

\section{Acidic colonic microclimate}

SIR, - We read with interest the article of $\mathrm{H}$ Vogelsang et al in the January issue (Gut 1988; 29: 21-6). We wonder, however, if the statistical results in Table 2 are correct. The authors state that the $\mathrm{H}_{2}$ production expressed as AUC-H2 (area under the curve of $\mathrm{H}_{2}$ ) after $20 \mathrm{~g}$ lactulose intake after three days of pretreatment with lactulose, is significantly less $(p<0.05)$ than the AUC-H2 after intake of $20 \mathrm{~g}$ lactulose before lactulose pretreatment.

After recalculating their figures which are given as mean (SEM), we find a value of 8523 (4355) (mean (SD)) before, and 5414 (5037) (mean (SD)) after three days' lactulose intake. As the authors mention that they used the unpaired two-tailed Student's $t$ test for their statistical analysis, the pooled SD has to be calculated, which is 4708 . With these values we find for $T$ a value of 1.23 , which corresponds with a $p$ value of $0 \cdot 24$.

Department of Internal Medicine,

M HIELE

Service of Gastroenterology,

University Hospital Gasthuisberg, 3000 Leuven, Belgium.

\section{Reply}

SIR, - Thank you very much for your critical reading of our paper. Your calculations concerning the statistical analysis of change of AUC- $\mathrm{H}_{2}$ after lactulose treatment are right. We have to apologise for our mistake which originated from a false asterisk written down during repeated corrections. The datacalculated on the computer - were, of course, correct and there was also a tendency of lower AUC- $\mathrm{H}_{2}$ after lactulose treatment running parallel to the change of $\max -\mathrm{H}_{2}$, but was not significant because of the relative high variance of changes of $\mathrm{AUC}-\mathrm{H}_{2}$. Therefore we failed to recognise this false asterisk being seemingly logical at this position.

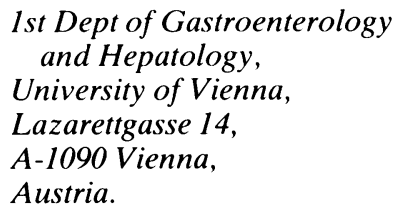

Antibiotic prophylaxis for endoscopic sphincterotomy SIR, - I wish to draw attention to the importance of making the correct choice of prophylactic antibiotic for endoscopic sphincterotomy (ES).

The Leicester series by Davidson et al (Gut 1988; 29: 114-20) reports significantly higher mortality and complications in comparison with the series reported by Martin and Tweedle from Manchester.' In the Manchester ES series of 81 patients reported, none had septic complications and the only death was from haemorrhage. In the Leicester ES series of 106 patients reported, $19 \cdot 5 \%$ had septic complications, and four of the five deaths related to ES were caused by septicaemia. Pre-existing cholangitis, however, was not statistically significant between the two series.

Gregg et $a l^{2}$ have shown that $14(70 \%)$ of 20 patients developed infected bile after ES even though all the patients had sterile bile previously. The predominant species were $E$ coli, enterococcus, Proteus mirabilis and Klebsiella. Pseudomonas introduction into the gall bladder bile after ES has been reported by Neoptolomos ${ }^{3} \mathrm{et} \mathrm{al}$.

In the Manchester ES series, mezlocillin $2 \mathrm{~g}$ IV was used as prophylaxis except where antibiotic treatment had already been instituted for the treatment of cholangitis. Although not stated in the article, the authors from Leicester have used cephazolin $1 \mathrm{~g}$ im as prophylaxis in a larger series over the same period reported previously. ${ }^{+}$Although both are broad spectrum antibiotics, pseudomonas is sensitive to mezlocillin but resistant to cephazolin.

Did the authors use cephazolin im as prophylaxis in the series reported? If so, the higher mortality and complications found in their series could be attributable to this difference in choice and route of administration of the prophylactic antibiotic.

J D ARNOLD

King's College Hospital Medical School, London.

\section{References}

1 Martin DF, Tweedle DEF. Endoscopic management of common duct stones without cholecystectomy. Br J Surg 1987; 74: 209-11.

2 Gregg JA, Girolami PD, Carr-Locke DL. Effects of sphincteroplasty on the bacteriologic characteristics of the common bile duct. Am J Surg 1985; 149: 668-71.

3 Neoptolemos JP, Carr-Locke DL, Fossard DP. Prospective randomised study of preoperative endoscopic sphincterotomy versus surgery alone for common bile duct stones. Br Med J 1987; 294: 470-4.

4 Leese T, Neoptolemos JP, Carr-Locke DL. Successes, failures, early complications and their management following endoscopic sphincterotomy: results in 394 consecutive patients from a single centre. Br J Surg 1985; 72: 215-9. 